\title{
Gold electrode modified by self-assembled monolayers of thiols to determine DNA sequences hybridization
}

\author{
MÍZIA M S SILVA ${ }^{\mathrm{a}}$, IGOR T CAVALCANTI ${ }^{\mathrm{a}}$, M FÁTIMA BARROSO ${ }^{\mathrm{b}}$, \\ M GORETI F SALES ${ }^{\mathrm{b}}$ and ROSA FIREMAN DUTRA ${ }^{\mathrm{a}, *}$ \\ ${ }^{a}$ Laboratório de Pesquisa em Diagnóstico-LAPED, Universidade de Pernambuco, Rua Arnóbio Marques, \\ 310, Santo Amaro, 50100060, Recife-PE, Brazil \\ ${ }^{\mathrm{b}}$ Requimte/Instituto Superior de Engenharia do Porto, Rua Dr. António Bernardino de Almeida 431, \\ 4200072, Porto, Portugal \\ e-mail: rosa.dutra@pq.cnpq.br; rfiremandutra $a$ yahoo.com.br
}

MS received 24 December 2009; revised 7 May 2010; accepted 1 June 2010

\begin{abstract}
The process of immobilization of biological molecules is one of the most important steps in the construction of a biosensor. In the case of DNA, the way it exposes its bases can result in electrochemical signals to acceptable levels. The use of self-assembled monolayer that allows a connection to the gold thiol group and DNA binding to an aldehydic ligand resulted in the possibility of determining DNA hybridization. Immobilized single strand of DNA (ssDNA) from calf thymus pre-formed from alkanethiol film was formed by incubating a solution of 2-aminoethanothiol (Cys) followed by glutaraldehyde (Glu). Cyclic voltammetry (CV) was used to characterize the self-assembled monolayer on the gold electrode and, also, to study the immobilization of ssDNA probe and hybridization with the complementary sequence (target ssDNA). The ssDNA probe presents a well-defined oxidation peak at $+0.158 \mathrm{~V}$. When the hybridization occurs, this peak disappears which confirms the efficacy of the annealing and the DNA double helix performing without the presence of electroactive indicators. The use of SAM resulted in a stable immobilization of the ssDNA probe, enabling the hybridization detection without labels. This study represents a promising approach for molecular biosensor with sensible and reproducible results.
\end{abstract}

Keywords. Single-stranded DNA; genosensor; self-assembled monolayer; gold functionalized electrode.

\section{Introduction}

Development of biotechnology and medicine allowed the detection of target single-stranded DNA (ssDNA) which is, currently, an area of research interest as it provides potential applications in gene transfection, accurate polymerase chain reaction for mutation detection, diagnosis of genetic diseases, species identification, and evolutionary analysis. ssDNA is generated during orchestrated cellular processes such as DNA replication, recombination and repair, as well as by spontaneous DNA damage events. ${ }^{1-7} \mathrm{Sev}-$ eral techniques are used for DNA detection; the conventional ones are based on the coupling of electrophoretic separations and radioisotopic detection. ${ }^{8,9}$ However, they are generally labour-intensive and time consuming, requiring well-trained technicians.

\footnotetext{
*For correspondence
}

Recent advancements in biotechnology have resulted in the development of rapid methods that reduce analysis time and offer great sensitivity and specificity in the detection of DNA, ${ }^{5}$ such as, fluorescence technique ${ }^{10}$ optical methods, quartz crystal microbalance ${ }^{11}$ and electrochemistry. ${ }^{12-14}$ Amongst them, electrochemical detection based on biosensor has attracted considerable interest due to the advantage of simplicity, low cost and high sensitivity. ${ }^{1,13}$ The genosensor seems to be excellent candidates for the rapid detection of pathogenic biological species of clinical interest. ${ }^{16-18}$

Different methods have been used to immobilize the DNA onto electrode surface such as, controlledpotential adsorption, ${ }^{19}$ entrapment in a polymer matrix, biotin-avidin interaction, and covalentbinding. ${ }^{1}$ Alkanethiol compounds are commonly used to form strong covalent bond on gold surfaces producing a well-ordered structure. Using this self- 
assembled monolayer (SAM) it is expected that biomolecules, enzymes and probe oligonucleotides, can be irreversibly immobilized on a variety of substrates without denaturation. ${ }^{20}$ SAM is a good strategy for linking biomolecules because, this technique allows an easy formations of monolayers, reasonable stability for extended period, allowing several reliable measurements. However, SAM also presents limitations, such as, immobilization of enzymes are very much sensitive towards changes in analytical parameters $(\mathrm{pH}$, temperature, etc.), a minor change in one of these parameters can sometimes be responsible for losing the biological activity. ${ }^{21}$ The literature describes numerous detection strategies for DNA hybridization, involving labelling DNA with metal nanoparticles and sophisticated sandwich assays using redox-active enzymes bound to the target DNA strands. ${ }^{16}$ Based on the detection of hybridization events, the target ssDNA is detected directly or by DNA electroactive indicators (metal coordination complexes, etc.), which form complexes with the nitrogenous bases of DNA. ${ }^{22}$ Oligonucleotides labelled with enzymes have been employed in hybridization detection protocols. ${ }^{6}$ Additionally, an hybridization detection scheme based on ferrocene modified adenine moieties was reported. ${ }^{23}$ Increased attention is given to direct label-free hybridization detection involving the intrinsic electroactivity of nucleic acids. This hybridization method, based on oxidation signal of probe on modified gold electrodes in electrochemical DNA biosensor, seems to be a simple, less time consuming and more applicable strategy in comparison with the others. ${ }^{24}$

In this study, a non-labelling electrochemical DNA biosensor based on SAM modified gold electrode for ssDNA detection was studied, using the covalent coupling of complex cysteamine (Cys)/ glutaraldehyde (Glu) as a cross-linking structure amino-functional, which allowed the DNA hybridization efficiently. These new electrochemical DNA based-biosensors offer new opportunities in the analytical field, increasing the applications of DNAbased-molecular diagnostics, taking full advantage of the existing modified electrode technologies.

\section{Experimental}

\subsection{Reagents}

Single stranded DNA (ssDNA from calf thymus and lyophilized, $\geq 65 \%$ ), double stranded DNA (dsDNA,
DNA from calf thymus), Glu (25\%), 2-aminoethanethiol or cysteamine (95\%) were purchased from Sigma Co. (MO, USA). Hydrogen Peroxide $30 \%(\mathrm{v} / \mathrm{v})$ and ethanol (99.5\%) were obtained from Labsynth (São Paulo, Brazil) and F. Maia Ltda. (São Paulo, Brazil), respectively. The ssDNA and dsDNA from calf thymus were diluted in ultra-pure water ( $1 \mathrm{mg} \mathrm{mL}^{-1}$ ) and kept frozen according to manufacturers' instructions.

All other chemicals were of analytical reagent grade. The Phosphate Buffer (PB; $0.1 \mathrm{~mol} \mathrm{~L}^{-1} \mathrm{pH} 7.0$ ) was used as electrolyte. In all prepared solutions, ultra-pure water was used as acquired from Millipore Milli- $Q^{\circledR}$ Ultrapure Water Purification Systems.

\subsection{Apparatus}

Cyclic voltammetry (CV) was carried out using a MPQG-01 potentiostate (Microquimica, Brazil) connected to a PC. All the measurements were made using a conventional three-electrode system. A platinum wire acted as the auxiliary electrode. All the potentials were referred to an $\mathrm{Ag} / \mathrm{AgCl} / \mathrm{KCl}$ saturated reference electrode. The gold electrode $(0.5 \mathrm{~mm}$ diameter, Microquimica, Brazil) was used as working electrode.

All the electrochemical experiments were carried out at room temperature $\left(25^{\circ} \mathrm{C}\right)$ without aeration. The potential scan was carried out between -0.5 and $+0.5 \mathrm{~V}$ at $50 \mathrm{mV} \mathrm{s}^{-1}$.

\subsection{Pretreatment of the gold electrode (AuE)}

The gold electrode (AuE) was mechanically polished with alumina slurry $(0.3 \mu \mathrm{m})$ followed by rinsing with distilled water and sonication (UltraSonic Cleaner USC 700, Unique, Brazil) in pure ethanol and water, for $2 \mathrm{~min}$. After mechanical cleaning, the gold electrode suffered a chemical treatment by immersion in a 'piranha solution' $\left(\mathrm{H}_{2} \mathrm{SO}_{4} / \mathrm{H}_{2} \mathrm{O}_{2}\right.$, $1: 3 \mathrm{v} / \mathrm{v}$ ) for $10 \mathrm{~min}$ at room temperature. Afterwards, the gold electrode was immersed in PB and 10 cycles were carried out between +0.2 and $+1.5 \mathrm{~V}$ at $50 \mathrm{mV} \mathrm{s}^{-1}$. Finally, the electrode was rinsed thoroughly with distilled water for $10 \mathrm{~min}$ and after exposed to UV radiation for $15 \mathrm{~min}$.

\subsection{Self-assembled monolayer and ssDNA immobilization}

The pretreated electrodes were immersed into $25 \mathrm{mmol} \mathrm{L}^{-1}$ ethanolic solution of Cys for $2 \mathrm{~h}$ at 
room temperature $\left(25^{\circ} \mathrm{C}\right)$ to allow an intimate contact between the gold and the thiol groups and subsequent formation of $\mathrm{Au}-\mathrm{Cys} \mathrm{SAMs}$ on the electrode surface. After that, the electrode was washed with distilled water. The immobilization of ssDNA was accomplished after incubating the $\mathrm{Au}-\mathrm{Cys}$ electrode in a Glu solution $\left(2.5 \%\right.$ of Glu in $0.1 \mathrm{~mol} \mathrm{~L}^{-1} \mathrm{~PB} \mathrm{pH}$ 7.0 at $4{ }^{\circ} \mathrm{C}$ for $50 \mathrm{~min}$ ). The electrode was then exhaustively washed with ultra pure water and incubated with ssDNA from calf thymus (probe ssDNA) prepared in $0.1 \mathrm{~mol} \mathrm{~L}^{-1} \mathrm{~PB} \mathrm{pH} 7.0$ at $10 \mu \mathrm{g} \mathrm{mL}^{-1}$. The incubation time was maintained for $1 \mathrm{~h}$ at room temperature $\left(25^{\circ} \mathrm{C}\right)$. Then, the electrode was washed for 2 min twice with PB buffer ( $\mathrm{pH}$ 7.0) to remove the non-binding probe ssDNA. The modified surfaces were then treated with glycine (dipped in $0 \cdot 1 \mathrm{~mol} \mathrm{~L}^{-1}$ glycine aqueous solution for $20 \mathrm{~min}$ ) to cap off any unreacted aldehyde groups following probe immobilization. The immobilization of ssDNA on the $\mathrm{Au}-\mathrm{Cys}-\mathrm{Glu}$ was scanned by cyclic voltammetry, continuously, in PB buffer solution.

\subsection{DNA hybridization}

The probe-modified electrode was incubated with a solution containing the DNA sequence complementary to the probe ssDNA to form a surface-bound duplex (dsDNA). The single stranded complementary ssDNA sequence was obtained by boiling native double-strand DNA from calf thymus in a water bath at $100^{\circ} \mathrm{C}$ for ca. 5 min followed by rapid cooling in an ice bath. Hence, target DNA $\left(20 \mu \mathrm{g} \mathrm{mL} \mathrm{mL}^{-1}\right)$ was incubated at room temperature $\left(\sim 25^{\circ} \mathrm{C}\right)$ while the incubation time was maintained at $30 \mathrm{~min}$. Subsequently, the gold electrode was washed twice with PB buffer ( $\mathrm{pH} \mathrm{7.0)}$ to remove the non-hybridized DNA probes. A control experiment regarding the hybridization was carried out by incubating the ssDNA probe immobilized with a non-complementary ssDNA sequence, which was obtained by boiling double-strand from Salmon Sperm DNA (Sigma No. D-1626). A scheme of immobilization and hybridization is shown in figure 1 .

\section{Results and discussion}

The electrochemistry of the ferri/ferrocyanide redox couple was used to study the chemisorptions of the SAM on the gold electrode. Figure 2 shows the behaviour of the gold electrode and the process of cleaning or surface preparation for the immobiliza- tion of ssDNA. An uncontaminated gold surface is important for the good chemisorption of thiol moiety for gold. ${ }^{21}$ In this study, the gold electrode surface was then mechanically polished with alumina, sonicated, and etched in a piranha solution to remove possible contaminant. Moreover, the electrode was submitted by repeated cycles (4 cycles) to remove residual contaminant until stable voltammogram was obtained. The cyclic voltammogram of gold electrode immersed in a solution of $10 \mathrm{mM}$ ferri/ ferrocyanide $(1: 1)$ shows a difference of redox peak of approximately $50 \mathrm{mV}$ and the amplitudes was practically equal (figure $2 \mathrm{a}$ ), it shows that the process of cleaning was satisfactory. When the polycrystalline gold electrode was exposed to a thiolbased solution a strong and stable linkage of S-Au occurs. ${ }^{25}$ This was confirmed by a decrease in peak current when the $\mathrm{Au}$ surface was exposed to $-\mathrm{SH}$ groups (Cys) for up to $2 \mathrm{~h}$ (figure $2 \mathrm{~b}$ ). This observation was attributed to a continuous layer forming on the electrode surface, which hindered the electron

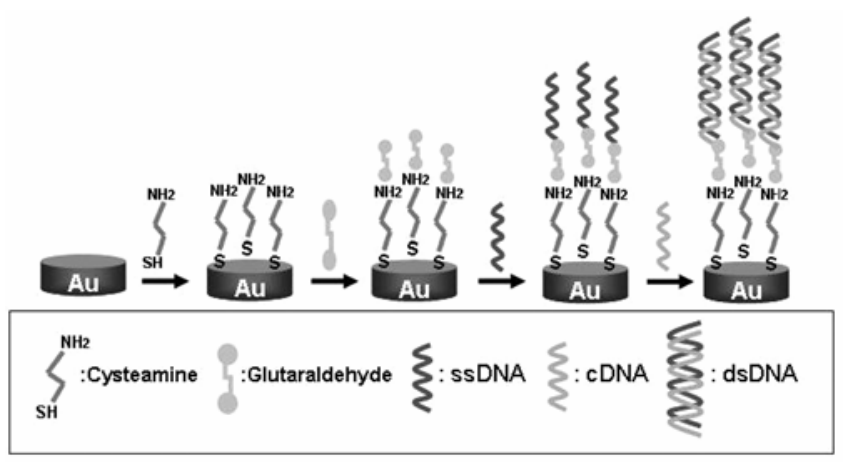

Figure 1. Formation of the thiol-based monolayer on gold surface for DNA immobilization and hybridization.

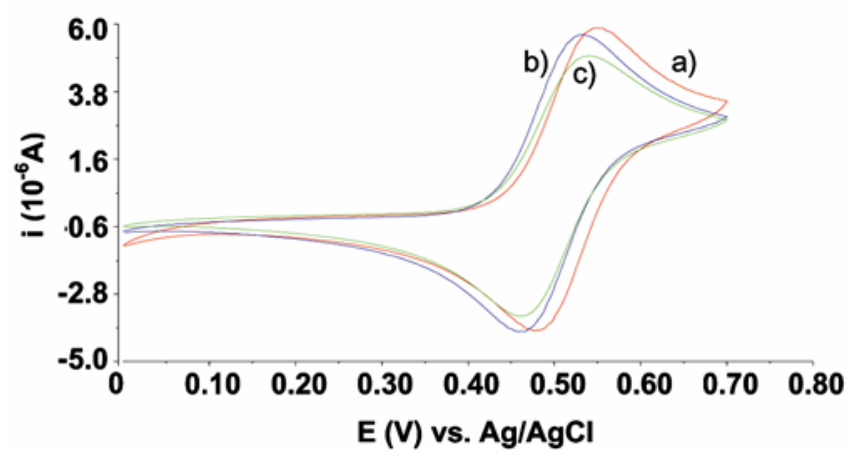

Figure 2. Cyclic voltammograms of (a) Au bare electrode; (b) Au-Cys-Glut; (c) Au-Cys-Glut-ssDNA modified electrode. Scan rate: $50 \mathrm{mV} \mathrm{s}^{-1}$ in $10 \mathrm{mM}$ of ferri/ ferrocyanide redox couple. 
transfer between the electroactive species and the electrode. After that, the modified electrode containing amino groups (Cys) was exposed to a solution of Glu at neutral $\mathrm{pH}$ to form a covalent bond $\mathrm{C}=\mathrm{N}$. Changes in interfacial properties by adding a thin polymeric layer is shown in the voltammogram (figure $2 \mathrm{~b}$ ) by a slight reduction in area and displacement of the electrolytic anode and cathode potential as resulting of a capacitive current. It is desirable that this change is slight, in fact, due to the necessity of a tightly binding of the compound Cys to gold and the alignment of self-assembled monolayers, which can result in a greater increase in faradaic current source. When the ssDNA is linked, a significant reduction in the electrochemical area is justified by the large amount of material assets (figure 2c).

The time contact of Cys with the gold surface used to form the $\mathrm{S}-\mathrm{Au}$ covalent linkage should be considered for the SAM construction. It is important to note that after a given time contact of the Cys solution with the gold surface used to self-assemble this monolayer, a specific number of ssDNA molecules are attached to the electrode surface. ${ }^{26}$ The optimal response of this genosensor was previously obtained within $2 \mathrm{~h}^{27,28}$ For lower time of contact, the analytical signals were lower, thus indicating that the gold surface had still active sites for sulfide linkage. For time of contact of Cys above $12 \mathrm{~h}$, the analytical signals also decreased. This behaviour may indicate the formation of disulfide bridges between two Cys molecules, decreasing the concentration of available - $\mathrm{SH}$ groups.

Cys reacts after with Glu, a molecule with two terminal aldehyde functions $(-\mathrm{CHO})$. Because of the polarization of the carbonyl bond $(-\mathrm{C}=\mathrm{O})$, the carbon atom of each carbonyl group becomes electrondeficient, acquiring a partial positive charge. This makes it susceptible to nucleophilic attack by an electron-rich chemical species. The Cys monolayer has free amine groups $\left(-\mathrm{NH}_{2}\right)$ that may carry out this reaction; the nitrogen atom attacks the carbon atom of the carbonyl group, producing a typical nucleophilic addition product $-\mathrm{C}(\mathrm{OH})\left(\mathrm{NH}_{2}\right)^{-}$. However, this is not a stable structure and the reaction proceeds with the elimination of one water molecule and subsequent rearrangement into a $-\mathrm{C}=\mathrm{N}-$ bond. Therefore, time and concentration are two important factors to develop a well-ordered monolayer, made by reacting Glu with the outer surface of Cys attached to gold. With a reduced time of contact between Glu solution and the Cys monolayer, the reaction may turn incomplete and only a few free carbonyl groups at the new assembled monolayer are found. An excess time of contact may promote cross linking reactions, where both carbonyl groups in each Glu molecule react with adjacent amines from the Cys monolayer. In this specific reaction one carbonyl group is left for subsequent binding ssDNA. A long time of contact between Glu and Cys monolayer may also allow the formation of byproducts from the nucleophilic attack of oxygen atoms to the electron-deficient carbon atom in nearby $\mathrm{C}=\mathrm{O}$ bonds. Nucleophilic oxygen atoms may result from remaining hydroxyl groups of the first nucleophilic addition product or from water molecules. All previous possibilities reduce the number of carbonyl groups at the outer surface of the monolayer, thus decreasing the number of active sites for subsequent binding of ssDNA.

The electrochemical signal of DNA sensors is mainly achieved by interaction of DNA probe with target analyte which can affect the electrochemical oxidation of guanine residues. Only guanine $(G)$ and adenine (A) bases are inherently electrochemically active at practical potentials. The ideal immobilization of ssDNA onto surface occurs when the probe is attached to the electrode through free bases with the purpose of subsequent hybridization. Analysing the figure 3 , it can be verified that during the cathodic scan an oxidation process occurs at about $+0 \cdot 158 \mathrm{~V}$. This process is irreversible and the oxidation peak is sharp and well-defined suggesting the immobilization of ssDNA, for an active surface of $5.5 \times 10^{-5}$ mol cm$~^{-2}$. There is a selective covalent coupling of Glu to the $3^{\prime}$ end of ssDNA, ${ }^{26}$ resulting in the stable and simple immobilization technique.

It is evident that the use of SAM technique to immobilize ssDNA is efficient, especially as compared with ssDNA direct adsorption on the electrode that was just dispersing DNA molecules on an electrode substrate until they were physically adsorbed onto the electrode (figure 4). As shown in figure 4a, no current peak of oxidation at $+0 \cdot 158 \mathrm{~V}$ was observed when the same ssDNA $\left(1 \mathrm{mg} \mathrm{mL}^{-1}\right)$ was directly immobilized on the gold electrode, under the conditions of $1 \mathrm{~h}$ at $25^{\circ} \mathrm{C}$. It is also important to elucidate the discrete reduction at $+0 \cdot 158 \mathrm{~V}$ on the current peak from direct adsorption of DNA (figure 4a). This reduction is due to binding of ssDNA on the gold electrode surface as resulted from positive potential applied during the immobilization enhancing the electrostatic attraction between the positively 
charged surface and the negatively charged sugarphosphate backbone of DNA. ${ }^{29}$

Increased attention has been given recently, to direct label-free electrochemical detection by monitoring the changes in some electrical parameter accrued from the hybridization event. Hybridization detection label-free was reported by Lucarelli and collaborators ${ }^{16}$ monitoring the decrease of the guanine peak of the immobilized probe (e.g. oligo $d(G) 20)$, following the addition of the complementary oligo $\mathrm{d}(\mathrm{C}) 20$ target $^{30}$ However, this procedure

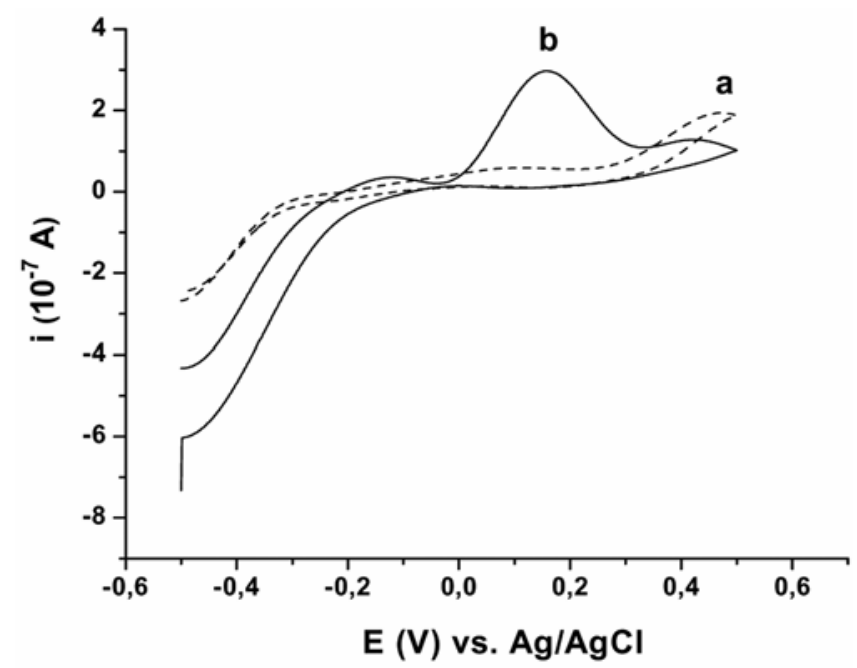

Figure 3. Cyclic voltammograms performed in modified Au-electrode. (a) Au-SAM; and (b) After ssDNA immobilization. Scan rate: $50 \mathrm{mV} \mathrm{s}^{-1}$ in $0.1 \mathrm{~mol} \mathrm{~L}^{-1}$ phosphate buffer $\mathrm{pH} 7 \cdot 0$.

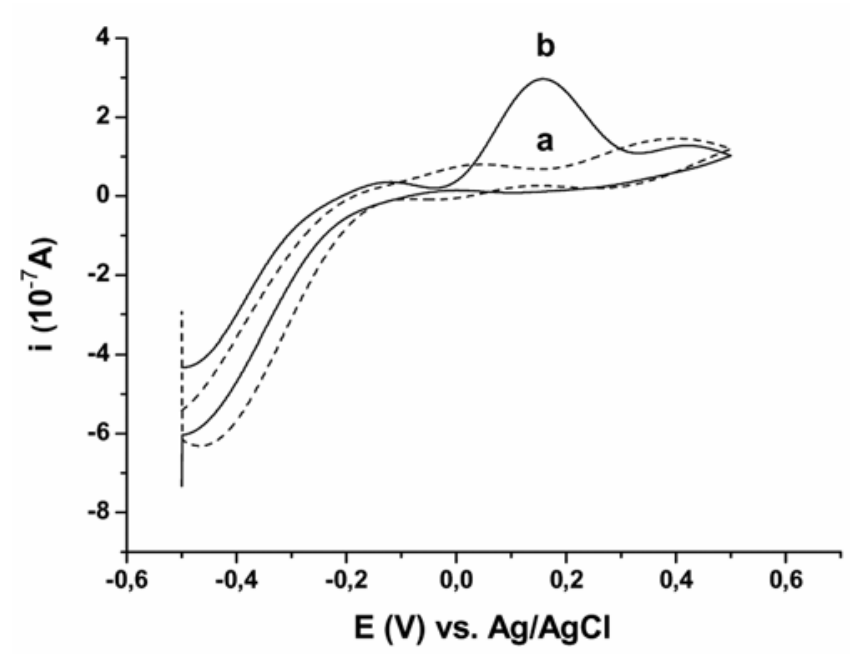

Figure 4. Cyclic voltammograms of (a) ssDNA direct absorption (pipetting $40 \mu \mathrm{L}$ of ssDNA directly) on $\mathrm{Au}$ electrode and (b) Au-SAM-ssDNA immobilization. Scan rate: $50 \mathrm{mV} \mathrm{s}^{-1}$ in $0 \cdot 1$ and $\mathrm{L}^{-1}$ phosphate buffer $\mathrm{pH}$ 7.0. was not applicable in most cases (e.g. for guanine containing targets). In this work, it was possible to characterize the electrochemical discrimination between the ssDNA and dsDNA probes by a low oxidation peak current of dsDNA when compared with the ssDNA oxidation process. This electrochemical evidences are not only because dsDNA is protected by hydrogen bonds of the double helix, but also because of its structural rigidity on the electrode surface. ${ }^{19}$

The phenomenon of the double helix was monitored when the dsDNA electrode was heated to

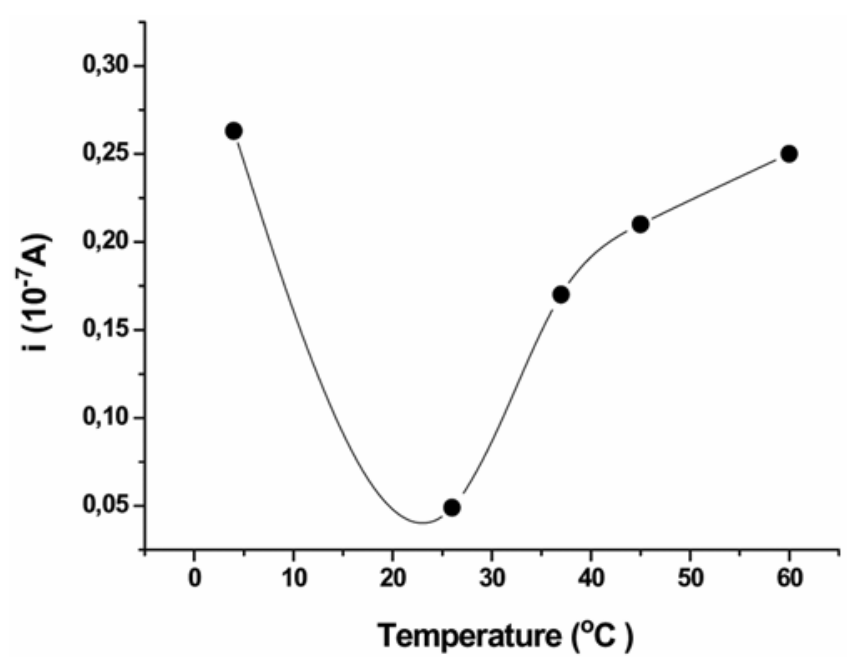

Figure 5. The hybridization of DNA probe was characterized with cyclic voltammetry (CV), in which the hybridization efficiency was optimized by varying temperature.

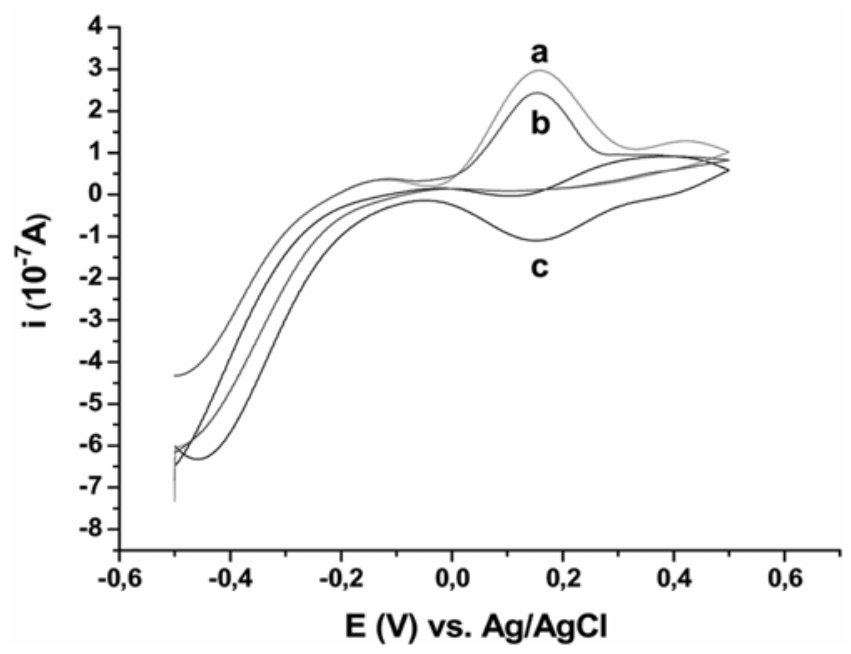

Figure 6. Cyclic voltammograms of (a) Au-SAMssDNA; (b) Au-SAM-ssDNA hybridization with noncomplementary ssDNA and (c) Au-SAM-ssDNA hybridization with complementary ssDNA. Scan rate: $50 \mathrm{mV} \mathrm{s}^{-1}$ in PB buffer $\mathrm{pH} 7 \cdot 0$. 
denaturation temperatures in order to form single strands and then cooled slowly to allow the DNA reform (renaturation) at regions of sequence complementarity and form a new 'hybridized' DNA molecule. A reduction of current oxidation peak appears in the hybridization. These results agreed with other studies found in the literature. ${ }^{31}$

The effect of incubation temperature on the charge of hybridization of immobilized ssDNA was studied. The electrode was incubated for $30 \mathrm{~min}$ with the target ssDNA. The cyclic voltammograms of different temperature of hybridization DNA was compared to ssDNA oxidation signal. Figure 5 shows that a maximum kinetics of hybridization was achieved at room temperature $\left(20\right.$ to $\left.26^{\circ} \mathrm{C}\right)$, with a reduction of current peak of oxidation at $+0 \cdot 158 \mathrm{~V}$. For temperatures higher than $47^{\circ} \mathrm{C}$, the charge of hybridization is strongly reduced by non-annealing of bases. ${ }^{32}$

According La-Scalea and collaborators, ${ }^{33}$ there is a relation between the dsDNA oxidation peak and the molecular weight of nucleic acids. Here, it was used a genomic DNA of long-chain bases, resulted by high molecular weight is a more evident electrochemical signal (figure 6a). Moreover, a selfassembled of thiol with short chain length (Cys with 2 carbons) leads to higher physical proximity of DNA sequence to electrode surface, facilitating charge transfers to the electrode surface and increasing guanine oxidation peak. Figure $6 \mathrm{~b}$ shows that the anodic peak current disappeared after hybridization. This inverted oxidation peak seems to be due to the saturation or excess of complementary ssDNA in competition with the hybridized target ssDNA. This anodicity is explained by the negative charges of sugars present in single stranded probes of deoxyribonucleic acid. The control experiment, carried out with a non-complementary ssDNA did not cause a significant reduction of the anodic peak (figure 6b).

\section{Conclusions}

This work described a simple label-free electrochemical DNA method for detection of target ssDNA. Immobilization of ssDNA on the gold electrode was possible by SAMs formation. SAM provides an easy method to functionalize a gold surface by forming a highly ordered organic film that resembles the biomembrane microenvironment. This method is simple and does not require an electroative species to generate an amperometric signal. It can be applied to food and environmental analysis as well as different clinical assays demanding quick responses for urgent diagnostic.

\section{Acknowledgements}

The authors thank Conselho Nacional de Desenvolvimento Científico e Tecnológico $(\mathrm{CNPq})$ and Consenlho de Aperfeiçoamento do Ensino Superior (CAPES) agencies of Brazil for financial support.

\section{References}

1. Zhang S S, Tan Q Q, Li X M and Li F 2008 Sens. Actuat. B Chem. 128529

2. Cubeddu L and White M F 2005 J. Mol. Biol. 353 507

3. Pividori M I, Merkoçi A and Alegret S 2001 Biosens. Bioelectron. 161133

4. Ge C, Miao W, Ji M and Gu N 2005 Anal. Bioanal. Chem. 383651

5. Pan J 2007 Biochem. Eng. 35183

6. Wang J 2002 Anal. Chim. Acta 46963

7. Gau V, Ma S-C, Wang H, Tsukuda J, Kibler J and Haake D A 2005 Methods 3773

8. Yan H, Zhang X, Shen Z and Seeman N 2002 Nature 41562

9. Gore J, Bryant Z, Stone M, Nollmann M, Cozzarelli $\mathrm{N}$ and Bustamante C 2006 Nature 439100

10. Liang M 2007 Environ. Sci. Technol. 42658

11. Su X, Lin C Y, O'Shea S J, Teh H F, Peh W Y X and Thomsen J S 2006 Anal. Chem. 785552

12. Palecek E and Jelen F 2002 Crit. Rev. Anal. Chem. 3 261

13. Gooding J J 2002 Electroanalysis 141149

14. Drummond T G, Hill M G and Barton J K 2003 Nat. Biotechnol. 211192

15. Pänke O, Kirbs A and Lisdat F 2007 Biosens. Bioelectron. 222656

16. Lucarelli F, Tombelli S, Minunni M, Marrazza G and Mascini M 2008 Anal. Chim. Acta 690(3) 139

17. Umek R M, Lin S W, Vielmetter J, Terbrueggen R H, Irvine B, Yu C J, Kayyem J F, Yowanto H, Blackburn G F, Farkas D H and Chen Y-P $2001 \mathrm{~J}$. Mol. Diag. 374

18. Williams E, Pividori M I, Merkoçi A, Forster R J and Alegret S 2003 Biosens Bioelectron. 19165

19. Mello L D, Hernandez S, Marrazza G, Mascini M and Kubota LT 2006 Biosens Bioelectron. 211374

20. Shabani A, Mak A W H, Gerges I, Cuccia L A and Lawrence M F 2006 Talanta 70615

21. Chaki N K and Vijayamohanan K 2002 Biosens Bioelectron. 1712

22. Erdem A, Kerman K, Meric B, Ozkan D, Kara P, Ozsoz M and Turk J 2002 J. Chem. 26851

23. Aude A-E, Navarro E, Spinelli N, Chaix C, Moustrou C, Mandrand B and Brisset H 2004 Bioorg. and Med. Chem. Lett. 14(10) 2439 
24. Kerman K, Kobayashi M and Tamiya E 2004 Meas. Sci. Technol. 15 R1-R11

25. Mendes R K, Carvalhal R F and Kubota L T 2008 J. Electroanal. Chem. $\mathbf{6 1 2} 164$

26. Bruno J G and Crowell R 2008 J. Biomol. Tech. 19(3) 177

27. Dutra R F, Mendes R K, Silva V L and Kubota L T 2007 J. Pharm. Biom. Anal. 431744

28. Sun J J, Xu J J, Fang H Q and Chen H Y 1997 Bioelectrochem. Bioenerg. 4445
29. Wan J, Rivas G, Fernandes J R, Paz J L L Jiang M and Waymire R 1998 Anal. Chim. Acta 375197

30. Lucarelli F, Marrazza G, Palchetti I, Cesaretti S and Mascini M 2002 Anal. Chim. Acta 46993

31. Jin Y, Yao X, Liu Q and Li J 2006 Biosens. Bioelectron. 221126

32. Kerman K, Morita Y, Takamura Y and Tamiya E 2003 Electrochem. Commun. 9(4) 705

33. La-Scalea M A, Serrano S H P and Gutz I G R 1999 Quim. Nova 2241 